\title{
COMPORTAMENTO DE CÓPULA E ARMAZENAMENTO ESPERMÁTICO NO CARANGUEJO HYPOCONCHA PARASITICA (PODOTREMATA: DROMIIDAE)
}

\author{
Bento, M.A.G. ${ }^{1, *}$; López Greco, L.S. ${ }^{2}$ \& Zara, F.J. ${ }^{1}$ \\ ${ }^{1}$ Universidade Estadual Paulista "Júlio de Mesquita Filho", laboratório de Morfologia de Invertebrados (IML), \\ Departamento de Biologia Aplicada, UNESP/14881-900, Jaboticabal, SP. \\ ${ }^{2}$ Universidad de Buenos Aires. Consejo Nacional de Investigaciones Científicas y Técnicas. Instituto de \\ Biodiversidad y Biología Experimental y Aplicada (IBBEA, CONICET-UBA). Facultad de Ciencias Exactas y \\ Naturales. DBBE. Buenos Aires, Argentina. \\ *Autor correspondente: malice.unesp@gmail.com
}

\begin{abstract}
Neste trabalho descrevemos o comportamento de cópula de Hypoconcha parasitica, em condições laboratoriais, e adicionalmente, analisamos a morfologia da espermateca e o padrão de armazenamento dos espermatozoides e fluido seminal. Os casais foram mantidos em aquários e os comportamentos de acasalamento foram filmados e quantificados. As espermatecas foram processadas seguindo as rotinas para microscopia eletrônica de varredura, histologia e histoquímica, com prévio tratamento em EDTA. O comportamento de corte e guarda copulatória são ausentes em H. parasitica. A transferência espermática ocorreu enquanto os casais encontravam-se em "postura bivalve". Três cópulas foram registradas, com machos sempre em intermuda, enquanto uma fêmea copulou logo após a muda e duas em intermuda. A duração média de cópula foi de 173,3 \pm 70 minutos. A espermateca forma uma sutura derivada dos seguimentos torácicos 7/8 e mostra-se recoberta exclusivamente por cutícula, seguindo o padrão de Podotremata. Esta cutícula está fortemente associada às fibras musculares, principalmente nas regiões mais distais, oposta a abertura terminal da espermateca. A organização da espermateca indica que o processo de liberação dos espermatozoides para a fertilização ocorre por meio de ação muscular exercida na parede da câmara (aumentando ou diminuindo o volume da espermateca). Assim, a distribuição da musculatura em Hypoconchinae é diferente do descrito para o Homolidae Paromola cuvieri, a qual é concentrada na abertura da espermateca. Como em Homolidae, o pleópodo 1 parece estar envolvido na movimentação de espermatozoides e ovócitos no momento da fertilização em H. parasitica. Portanto, a morfologia da espermateca e estruturas associadas trazem novas informações sobre os mecanismos envolvidos na reprodução de caranguejos primitivos e como ocorreu a modificação desta estrutura armazenadora entre os Podotremata.
\end{abstract}

Palavras-chave: caranguejos primitivos; espermateca; histologia; ovulação; reprodução.

Financiamento: MS - FAPESP \#2016/10394-4 (Maria Alice Garcia Bento); FAPESP BIOTA\#2010/50188-8; CAPES CIMAR II 1989/2014 - 23038.004309/2014-51. 